\title{
Corrigendum: Bovine Tuberculosis in Britain and Ireland - A Perfect Storm? the Confluence of Potential Ecological and Epidemiological Impediments to Controlling a Chronic Infectious Disease
}

\author{
A. R. Allen ${ }^{\star \dagger}$, R. A. Skuce and A. W. Byrne ${ }^{\dagger}$ \\ Veterinary Science Division, Agri-Food and Biosciences Institute, Belfast, United Kingdom
}

Keywords: Mycobacterium bovis, Britain and Ireland, eradication, persistence, epidemiology

\section{A Corrigendum on}

\section{OPEN ACCESS}

Approved by:

Frontiers Editorial Office

Frontiers Media SA, Switzerland

*Correspondence:

A. R. Allen

adrian.allen@afbini.gov.uk

†These authors have contributed equally to this work

Specialty section: This article was submitted to Veterinary Epidemiology and Economics,

a section of the journal

Frontiers in Veterinary Science

Received: 13 June 2019 Accepted: 14 June 2019 Published: 02 July 2019

Citation:

Allen AR, Skuce RA and Byrne AW

(2019) Corrigendum: Bovine Tuberculosis in Britain and Ireland - $A$ Perfect Storm? the Confluence of Potential Ecological and Epidemiological Impediments to Controlling a Chronic Infectious Disease. Front. Vet. Sci. 6:213. doi: 10.3389/fvets.2019.00213
Bovine Tuberculosis in Britain and Ireland - A Perfect Storm? the Confluence of Potential Ecological and Epidemiological Impediments to Controlling a Chronic Infectious Disease by Allen, A. R., Skuce, R. A., and Byrne, A. W. (2018). Front. Vet. Sci. 5:109. doi: $10.3389 /$ fvets.2018.00109

In the original article, there was an error. The tipping point of R0 was given as "0," while it should have stated "1."

A correction has been made to the Conclusions section, paragraph five:

\begin{abstract}
"A potential criticism of our focus on some of these factors, is that even if they did have a significant effect on bTB epidemiology, that effect may be very small and therefore, any intervention would potentially not be practical or cost efficient. However, in the absence of firm evidence either way, this criticism could appear to be somewhat pessimistic. The reproductive index (R0) for bovine TB between cattle in Britain has been estimated to be low - 1.1 (228). Between badgers, R0 has also been observed to be low - ranging from 1.03 to 1.19 (223). Between species R0 has recently been estimated to be in the region of $0.05(60)$. These results suggest that not much effort may be needed to tip the R0 (of the twohost system) below one and drive the epidemic to extinction. It may well be that targeted intervention on multiple factors of small effect, when combined with the larger effects of the nationally managed eradication schemes, could help achieve this goal. In effect, we are suggesting that addressing some of the potential factors identified here, may result in an aggregation of marginal gains that takes the standard eradication scheme protocol as its base line, and applies an ecosystem management approach to drive down remaining infection."
\end{abstract}

The authors apologize for this error and state that this does not change the scientific conclusions of the article in any way. The original article has been updated.

Copyright () 2019 Allen, Skuce and Byrne. This is an open-access article distributed under the terms of the Creative Commons Attribution License (CC BY). The use, distribution or reproduction in other forums is permitted, provided the original author(s) and the copyright owner(s) are credited and that the original publication in this journal is cited, in accordance with accepted academic practice. No use, distribution or reproduction is permitted which does not comply with these terms. 